\title{
Topical Betaxolol Hydrochloride for the Treatment of Superficial Infantile Hemangiomas: A Single Institutional Retrospective Study
}

Hong Li

First Affiliated Hospital of Xinjiang Medical University

Chen-Xi Li ( $\sim$ lichenxi89@yahoo.com)

University Medical Center Hamburg-Eppendorf

Yu-Chuan Zhou

First Affiliated Hospital of Xinjiang Medical University

Zhong-Cheng Gong

First Affiliated Hospital of Xinjiang Medical University

Bin Ling

First Affiliated Hospital of Xinjiang Medical University

\section{Research Article}

Keywords: Infantile hemangioma, $\beta$-adrenergic receptor blocker, Betaxolol hydrochloride, Topical administration.

Posted Date: February 19th, 2021

DOI: https://doi.org/10.21203/rs.3.rs-209620/v1

License: (c) (7) This work is licensed under a Creative Commons Attribution 4.0 International License. Read Full License 


\section{Abstract \\ Background and Objectives:}

Beta-blockers have gradually become an attractive option for the treatment of infantile hemangiomas (IHs). Topical application of beta-blockers is more preferred over oral administration since their potential systemic adverse effects. Besides timolol, as the mainstream medication for superficial IHs, however other types of beta-blockers are rarely reported. To develop a brand-new effective approach, in this present study, betaxolol as a topical treatment for IHs was specifically observed and recorded.

\section{Methods}

83 infants with superficial hemangiomas admitted to the First Affiliated Hospital of Xinjiang Medical University from January 2018 to May 2019 were all treated by topical application of betaxolol. The changeable indicators such as color, size, tension and thickness were monthly recorded and evaluated according to visual analog scales. Multi-factor analysis of variance (MANOVA) with repeated measurements and Kruskal-Wallis $\mathrm{H}$ nonparametric test were performed to compare the clinical effectiveness across different groups.

\section{Results}

After six months of treatment, 33.78\% (25/74) got excellent results, 55.41\% (41/74) had good response, $8.11 \%$ (6/74) had moderate response and 2.70\% $(2 / 74)$ had poor response respectively. During the whole procedure, neither local discomforts nor systemic complications had been found. There was no significant difference in gender and location of occurrence among groups $(P>0.05)$, while the effect of topical application of betaxolol was optimum in the children aged $0-3$ months $(P=0.002)$. None of three age groups had statistically significant discrepancy of heart rate and blood pressure after accepting treatment (one month, $P=0.618$; four months, $P=0.138$; six months, $P=0.757$ ).

\section{Conclusions}

Our study showed that topical administration of betaxolol was effective and well-tolerated for superficial IHs, particularly in the early proliferative stage. However, its safety and efficacy need continuous studies to be confirmed.

\section{Introduction}

As the most commonly benign vascular neoplasms among infancy (affect $4 \%-10 \%$ of infants), infantile hemangiomas (IHs) present early in life occurring with a female to male ratio of 3:2 approximately. ${ }^{1}$ In general terms, IHs appear as the precursory lesion, i.e. a rosy spot, telangiectatic macules or limited areas with bruises, ${ }^{2}$ and they are characterized by rapid growth in the first months of postnatal stage which followed by a protracted period of relative stabilization and then regressed slowly. ${ }^{3-4}$ Due to IHs' clinical manifestation combined with ultrasonography, the diagnosis can be made typically. Moreover, based on the extent and degree of involvement of surrounding tissues, IHs can be classified into three categories: superficial, mixed and deep type. ${ }^{5-6}$ Despite most IHs have the nature to self-limit as well as the vast majority of superficial ones are capable to fade away spontaneously without any medical intervention, there still exist several complications like ulceration, infection, malformation, disfiguration, visual impairment, unconscious hemorrhage, and even airway obstruction. ${ }^{7-8}$ Of $\mathrm{IHs}$, around $60 \%$ can be found in the head and neck area, preferentially occurred on the face, eyelids, ears, lips, cornea or genitalia, whereas about $25 \%$ and $15 \%$ respectively located in the trunk and extremities. Given the possibility of negative emergence, for instance functional impairment, morphological deformation or general complications, it is necessary to intervene as soon as possible. ${ }^{9-12}$ Treatments aimed at superficial IHs have gone through intralesional injection, local laser radiation, oral medication, and finally topical delivery of remedy. ${ }^{13}$ Since Léauté-Labrèze et al ${ }^{14}$ first reported that propranolol had a significant effect on hemangiomas of infancy, many kinds of $\beta$-blockers are being more and more recommended than any other therapeutic schedules for clinical application. ${ }^{10,15}$ However, not only were identified sorts of serious side-effects after oral administration of $\beta$-blockers (e.g., cardiovascular risks like hypotension, bradycardia or atrioventricular block; metabolic risks like hypoglycemia, hyperkalemia in ulcerative IHs; respiratory risks like bronchial spasm or asthma; neurological disorders like relevant epilepsia or transient ischemic stroke; and abnormalities occurred in eyes, heart and blood vessels of head and neck), ${ }^{16-18}$ but also it is difficult for drug concentration to act precisely on lesional locality via systemic circulation. Hence, the local administration of $\beta$ blockers represented by propranolol has been successively launched in clinical practice, until now timolol as the first-line drug has gradually become the main topical therapy for superficial IHs. ${ }^{6,19-20}$ Nevertheless, either some adverse effects that still exist or irresponsive / allergic to timolol, an alternative option should be prepared.

Betaxolol, which is a relatively selective $\beta-1$ adrenergic receptor blocker, initially emerged for ophthalmological disorders, and has almost identical function with timolol in lowering intraocular pressure. ${ }^{21}$ Furthermore, for structure and efficacy, betaxolol is practically as same as atenolol which is a good substitute to selective $\beta$-adrenergic-receptor blocker for IHs with fewer adverse events. ${ }^{22-24}$ More importantly, it has been confirmed that betaxolol has approximately ten times higher skin permeability than timolol because betaxolol is more lipophilic, whilst that makes topical application of betaxolol possible to achieve higher concentration at the same dosage over the superficial IHs. ${ }^{25-26}$ Considering no clinical data on the use of betaxolol for treating $\mathrm{IHs}$, this present study is the first description focused on the characteristics of topical administration of betaxolol hydrochloride in superficial IHs and may provide preliminary information for a new idea. 


\section{Patients And Methods}

This was a retrospective, observational clinical study involving 74 infants. All infants were recruited from the Outpatient of Oncological Department of Oral and Maxillofacial Surgery, the First Affiliated Hospital of Xinjiang Medical University, China, between January 2018 and May 2019. The protocol of study was approved by the Ethics Committee, Stomatology School of Xinjiang Medical University, The First Affiliated Hospital of Xinjiang Medical University (approval no. K202007-03), and the informed consents were signed by all the guardians. All data generated or analysed during this study are included in this published article.

Eligible subjects were infants aged younger than 12 months. The inclusion criteria were as followed: a. infants suffered from superficial hemangiomas who had not accepted any previous treatment; b. the diagnosis was confirmed by the criteria of International Society for the Study of Vascular Anomalies (ISSVA). ${ }^{27}$ The following as exclusion criteria were: a. infants had other types of vascular anomalies besides superficial hemangiomas; $b$. the general condition was unhealthy which amalgamated with fever, hypotension, atrioventricular block, bradycardia, pneumonia, bronchial asthma or diarrhea; c. infants had contraindications of betaxolol hydrochloride; $d$. during the clinical treatment, infants took $\beta$-agonist, or received medication other than $\beta$-blockers.

All infants met the selective criteria of study were assigned into three groups according to their age: a. 0-3 months; b. 3-6 months; c. 6-9 months. The general characteristics of infants, particularly the description of their hemangiomas, are shown in Table 1. Prior to treatment, the admitted infants well-received relevant examinations completely, which consisted of ultrasonography, electrocardiogram, blood routine examination, blood glucose concentration, serum potassium concentration and test of hepatic and renal function, in order to evaluate vital signs as well as recognize contraindications. Infants of this analysis only accepted betaxolol hydrochloride as topical administration apart from any other therapies. Specific therapeutic regimen was as followed: sterile gauze soaked fully of $0.25 \%$ betaxolol hydrochloride ophthalmic suspension (catalog $\mathrm{nr}$. 111820 , content $5 \mathrm{ml}$ : $12.5 \mathrm{mg}, \mathrm{S}$.A. ALCON-COUVREUR N.V.) was applied to cover hemangioma lesion three times per day (every six to eight hours); the dosage kept $30-40 \mu \mathrm{l} / \mathrm{cm}^{2}$ on surface and each time lasted 5-15 minutes (depending on the thickness of hemangioma and the reaction to treatment); preventing drugs infiltrating into eye or reproductive tract.

Parents were required to closely monitor the changes of complexion, heart and respiration rate after each local medication. Especially, the heart rates of preand post treatment, rest-activity and sleep-wake should be recorded. Once they had lower heartbeats than the normal minimum (neonate 120 /min, infant 100 /min), the drug must be stopped immediately. In case of ulceration appeared, it was necessary to avoid topical drugs on the wound. The whole process sustained for six months. Through each subsequent visit monthly, the same doctor took a standardized digital photograph and emphasized on checking heart rate (HR) and blood pressure (BP). Last but not least, in line with the extent of IHs regression, withdrawal of topical betaxolol was assessed. What should be recommended was that, gradual reduction or proper decrease the frequency of use until final discontinuing, so as to avoid drug withdrawal symptom. Every patient needed to be followed up for half a year after the treatment.

Based on clinical photographs, the efficacy of topical betaxolol hydrochloride was estimated by visual analog scale (VAS) at the onset, during and in the end of treatment separately. VAS for color (VAS-C) and for size, tension and thickness (VAS-STT), with scores ranging from -100 to 100 , were assessed outcome measures. Among them, $-100,0$, and 100 respectively signified doubling in size, no change, and complete healing for VAS-SEV, whilst doubling in intensity of color, no change, and complete absence of discoloration contrasted by the surrounding skin. Therapeutic response was graded into four levels: 1 . class I, excellent (scores ranging from 76-100); 2. class II, good (scores ranging from 51-75); 3. class III, moderate (scores ranging from 26-50); 4. class IV, poor (scores <25). Classes I and II were regarded as effective cases. ${ }^{20,28-30} \mathrm{~A}$ panel of three specialists independently recorded the outcomes, and any discrepancies among them were resolved by discussion.

Statistical analysis of all data was performed by Statistical Package for Natural Science (IBM SPSS version 22.0, New York, USA) and expressed as mean \pm standard deviation (SD). Kruskal-Wallis $\mathrm{H}$ test was applied to contrast the clinical responses for the differences across three age groups. The multi-factor analysis of variance (MANOVA) followed by multivariate analysis was employed to detect the difference between the two kinds of VAS scores among the age groups at three time points after topical treatment. Tukey HSD test was used for calculating the distinction of BP and HR between every time point and baseline point separately. For the sake of comparison, $P<0.05$ was considered statistically significant. GraphPad Prism software version 6.0 (Graph Pad Software Inc., San Diego, California, USA) was performed for plotting values. Adobe Photoshop version CC 16.0 (Adobe Systems Software Ireland Ltd, San Jose, California, USA) was for drawing diagrammatic sketch.

\section{Results}

Even though we launched treatment for a total of 83 infants with topical betaxolol hydrochloride initially, 9 were excluded from the final analysis because 5 were lack of photograph records, 2 had to alter regimen to oral propranolol, and 2 were lost to follow-up. Eventually, there left 74 subjects characterized by dominancy in females with a ratio of 2.4:1 versus males (52 females, 22 males). The mean age of these infants was 4.5 months ranging from 2.5 to 37 weeks. For the classification of superficial hemangioma, plaque was the predominant type (44.59\%). The primary location of lesions distributed in head and neck region (27), trunk (22) and extremities (25). Baseline data and implement scheme were shown in Table 1 and Figure 1 in detail.

Clinical responses to topical betaxolol hydrochloride after six-month therapy are summarized in Tables 2 . There was no significant difference in the effective rate between distinct genders and disease sites. The effective rate was higher in children under three months old $(96.97 \%, 32 / 33)$ than at three to six months $(95.24 \%, 20 / 21)$ than at six to nine months $(70 \%, 14 / 20)(P=0.002)$. With the progress of treatment, both VAS-C and VAS-STT scores were also appeared an overall upward trend Figure 2. A significant linear relationship either between time and VAS-C $(P=0.001)$ or VAS-STT scores $(P<0.001)$ was demonstrated under the mixed-effect model. The therapeutic efficacy of each age group became an improved response over time Table 3 . In regard to the results of BP and $\mathrm{HR}$, at three independent time point after treatment, none of three age groups had statistically significant discrepancy (one month, $P=0.618$; four months, $P=$ 0.138 ; six months, $P=0.757$ ) Tables 4 . No recurrent situation as well as systemic or local complications were discovered during the follow-up period. The 
distribution of original lesion of all the patients is shown in Figure 3. According to their different areas, there may be involved different potential high-risks. Firstly, IHs in maxillofacial and cervical region have a high risk of scarring, and IHs' association with PHACE syndrome* should be vigilant especially for the big ones. Besides, IHs within orbital region pose a hazard to vision affection; severe ones occurred in ear, nose and lip may cause permanent distortion or disfigurement of anatomic landmarks. Secondly, numerous lesions of torso (beyond five, or even more cutaneous hemangiomas) are potential to associate with hepatic hemangiomas. Herein, genital, perineal or perianal IHs may increase the risk of ulceration; it is also necessary to pay attention to prevention for IHs along with decubitus in posterior trunk; IHs invaded in lumbosacral or perineal area should be noticed for LUMBAR syndrome*. Thirdly, IHs located in extremities may be easily jeopardized into permanent hyperplasia or atrophy of skin tissue. Typical examples are illustrated in Figure 4 . Among them, Patient 1 is a 3-month-old girl with superficial IH located in left nipple; patient 2 is a 7 month-and-24 day-old girl with superficial IH located in left anterior thoracic region; patient 3 is a 2 month-and-2 week-old girl with superficial IH located in interior region of left lower leg; patient 4 is a 2-month-old boy with superficial IH located in left middle toe.

\section{Discussion}

It has been reached a consensus that more aggressive interventions should manage higher risks for complications, especially prioritized to possibly functional impairments and potentially life-threatening symptoms. After a constant-growing development treating against IHs, including surgery, photodynamic therapy, interventional sclerotherapy, and oral corticosteroids, propranolol as a revolution was welcomed in the year of $2008 .{ }^{14}$ Propranolol that is only available as systemic medication in most countries, however, may cause adverse effects via blood circulation. Even though some of them like hypotension, bradycardia, hypoglycemia, diarrhoea and sleep disturbance can be self-limited, ${ }^{31}$ anxieties concerned on neurocognitive capacity have been recently proposed. ${ }^{32}$ Since then, raising numbers of pediatric or dermatological specialists have conducted lots of clinical researches about diverse beta blockades treating IHs, and suggested local administration to point at superficial hemangiomas as well. ${ }^{33}$ Along with the very first report of a successful outcome after adopting timolol solution as a topical treatment for a four-month-old girl with a superficial capillary hemangioma located in her left eyelid, ${ }^{34}$ a series of relevant studies were confirmed subsequently. ${ }^{20,29-30,35}$ Nevertheless, with the deep-going development of clinical studies concentrated on topical timolol for superficial hemangioma, several side-effects and adverse events were also pointed out. ${ }^{29,36-40}$

Betaxolol, a relatively selective $\beta$-1 adrenergic receptor blocker, originally as a satisfactory remedy for glaucoma, has been widely used for more than approximately thirty years. Aside from several principal self-restrictive adverse effects containing local pruritus, bronchial spasm, hypotension and hypoglycemia found in rare cases, betaxolol always proves its safety, stability and efficiency. In this study, the overall rate of clinical effectiveness was $89.19 \%$ (66/74), whereas only 2 cases changed into oral propranolol because of poor response, and no one arose adverse effects. These results were better than those stated by Pope and Chakkittakandiyil (2010), ${ }^{39}$ Chakkittakandiyil et al (2012), ${ }^{41}$ Gong et al (2015), ${ }^{30}$ Püttgen et al (2016), ${ }^{20}$ and Wu et al (2018). ${ }^{42}$ Expected consequences might result either from the low density of intracorporal distribution via topical application, or from the less drug concentration itself ( $0.25 \%$ betaxolol hydrochloride versus $0.5 \%$ timolol maleate). Both sides could notably reduce the absorption inside bloodstream, while topical betaxolol made the infants' prognosis satisfactory. As an aside, we also proved the conclusions of Chantasart D et al ${ }^{25}$ and Zhang Q et al ${ }^{26}$ that, a small amount of betaxolol hydrochloride $(0.25 \%)$ can work the same or even better than timolol maleate $(0.5 \%)$, arising from its superior cutaneous permeation because of stronger liposolubility Table 5. Accordingly, less topical betaxolol hydrochloride has opportunity to pass blood-brain barrier which can bring about fatigue, anxiety and sleep disturbance.

On-going researches involved in mechanisms have found that, $\beta$-blockades make the actions of matrix metalloproteinase (MMP), endothelial nitric oxide synthase (ENOS), vascular endothelial growth factor (VEGF), and basic fibroblast growth factor (BFGF) suppressed by inhibiting $\beta$-adrenergic receptor, so as to further lead to proangiogenic signal blockage, and finally result in arrest of hemangioma growth. ${ }^{43-45}$ Remarkably, $\beta$-blockers may not participate in one single mechanism, but in a multiple combinations of regulations of anti-hemangioma passways Figure $\mathbf{5}$. Nonetheless, how the $\beta 1$-blocker impacts on the promotion of anti-hemangioma efficacy is still poorly understood.

Our present study also discovered that, the children aged younger than three months have the most effective outcomes (32/33, 96.97\%) compared with those in three-to-six $(20 / 21,95.24 \%)$ and six-to-nine months $(14 / 20,70.00 \%)$. What is more is that, children within six months have a similar effectiveness but they are much more than the older-than-six children. That is probably in line with the process of development of IHs, which can be divided into proliferation, regression and regressive completion stage typically. In addition, the proliferation stage is comprised of two representative periods of rapid growth within one year after birth: one is four to six weeks postnatally; another is four to five months. Our results possibly imply that betaxolol played a key role in preventing sorts of cytokines from hemangiogenesis promotion, and consequently medical interventions have better expectations within IHs' proliferation stage. The recordation of HR and BP after infants' acceptance of topical betaxolol therapy supported that no obvious abnormal HR and BP fluctuation appeared in three age groups. It is worth mentioning that, only a minor unexpected result of HR $(95.90 \pm 6.05 \mathrm{Bpm})$ was observed in the 6-9 months group at the end of therapy, and no relevant cardiac symptoms behaved though. We believe, on one hand, the age of this group is close to one-year old at that time, so the HR of them is nearly $90 \mathrm{Bpm}$ (prescribed minimum of normal HR of children aged 1-3 years old) as physiological changes. On the other hand, under normal circumstances, from birth the BP of children is slowly rising while their HR is falling slowly. The most important is, these physiological changes were not destroyed during the whole procedure of treatment according to our recordation.

\section{Conclusion}

This proof of this pilot study reported betaxolol hydrochloride, $0.25 \%$, suspension, a relatively selective $\beta-1$ adrenergic receptor blocker in topical formulation, was safe and effective for treatment of 74 cases with superficial IHs for the first time. Despite no inhibition of hemangioma progression after accepting topical betaxolol of two subjects, almost all infants showed well-tolerated responses and no one complained any adverse events. This preliminary work supposes that topical betaxolol hydrochloride, $0.25 \%$, suspension is a promising substitute for timolol maleate. Further double-blind, randomized controlled 
trials and prospective cohort studies are required to substantiate the safety and efficacy of betaxolol hydrochloride, $0.25 \%$, suspension for curing superficial IHs.

\section{List Of Abbreviations}

$\mathrm{IH}$

infantile hemangioma, ISSVA:the International Society for the Study of Vascular Anomalies, HR:heart rate, BP:blood pressure, HSD:honestly significant difference, VAS:visual analog scale, VAS-C:VAS for color, VAS-STT:VAS for size, tension and thickness, MMP:matrix metalloproteinase, VEGF:vascular endothelial growth factor, BFGF:basic fibroblast growth factor, ENOS:endothelial nitric oxide synthase.

\section{Declarations}

Ethics approval and consent to participate: The studies involving human participants were reviewed and approved by the Ethics Committee, Stomatology School of Xinjiang Medical University, The First Affiliated Hospital of Xinjiang Medical University (approval no. K202007-03). All methods involved in this study were carried out in accordance with relevant guidelines and regulations which were formulated by the identical group. Written informed consent to participate in this study was provided by the participants' legal guardian/next of kin.

Consent for publication: All the patients' legal guardian/next of kin gave their consent for information about their children to be published in $B M C$ Pediatrics. All authors approved the final manuscript as submitted and agree to be accountable for all aspects of the work.

Availability of data and materials: The raw data supporting the conclusions of this article will be made available by the authors, without undue reservation.

Competing interests: The authors declare that they have no competing interests.

Funding: All phases of this study were supported by Western Stomatological Clinical Research Foundation of Chinese Stomatological Association (grant number: CSA-W2019-01).

Authors' contributions: Dr. Hong Li drafted the initial manuscript, and carried out the initial analyses; Dr. Chen-Xi Li conceptualized and designed the study, designed the data collection instruments, optimized statistical methods, and critically revised the manuscript for important intellectual content; Dr. Yu-Chuan Zhou collected data, took in charge of follow-up assignment, and reviewed the manuscript; Prof. Zhong-Cheng Gong conceptualized and designed the study, and reviewed and revised the manuscript; Prof. Bin Ling conceptualized and designed the study, coordinated and supervised data collection, and reviewed and revised the manuscript.

Acknowledgements: Thank you to all the members of Oncological Department of Oral and Maxillofacial Surgery, The First Affiliated Hospital of Xinjiang Medical University for their industrious and meticulous work. Their dedication and devotion have everything to do with this publication.

\section{Article Summary}

Through the source of The First Affiliated Hospital of Xinjiang Medical University Clinical Databases, this study captures the therapeutic effect of betaxolol in superficial infantile hemangiomas.

\section{What's Known on This Subject}

Multiple medical regimens are involved in IHs, but the toxicity and side-effects of medication still exist. Many studies have indicated that some beta-blockers are capable to inhibit tumor growth, but the therapeutic effectiveness is not as good as expected.

\section{What This Study Adds}

Betaxolol is one of the selective beta-blockers, has better medicinal properties than what reported in the past. What is important is that, this medication is applied as therapeutic administration for superficial IHs for the first time.

\section{References}

1. Grzesik P, Wu JK. Current Perspectives on the Optimal Management of Infantile Hemangioma. Pediatric Health Med Ther. 2017;8:107-116. doi: 10.2147/PHMT.S115528

2. Vega Mata N, Lopez Gutierrez JC, Vivanco Allende B, et al. Different clinical features of acral abortive hemangiomas. Case Reports in Dermatological Medicine. 2017;2017:2897617. doi: 10.1155/2017/2897617.

3. Wang C, Li Y, Xiang B, et al. Quality of life in children with infantile hemangioma: a case control study. Health and Quality of Life Outcomes. 2017;15(1):221. doi: 10.1186/s12955-017-0772-z.

4. Baselga E, Roe E, Coulie J, et al. Risk factors for degree and type of sequelae after involution of untreated hemangiomas of infancy. JAMA Dermatology. 2016;152(11):1239-43. doi: 10.1001/jamadermatol.2016.2905.

5. Holland KE, Drolet BA. Approach to the patient with an infantile hemangioma. Dermatologic Clinics. 2013;31(2):289-301. doi: 10.1016/j.det.2012.12.006

6. Gan LQ, Wang H, Ni SL, et al. A prospective study of topical carteolol therapy in Chinese infants with superficial infantile hemangioma. Pediatr Dermatol. 2018;35(1):121-125. doi: 10.1111/pde.13361. 
7. Kilcline C, Frieden IJ. Infantile hemangiomas: how common are they? A systematic review of the medical literature. Pediatr Dermatol. 2008;25(2):168-173. doi: 10.1111/j.1525-1470.2008.00626.x.

8. Villalba-Moreno AM, Cotrina-Luque J, Del Vayo-Benito CA, et al. Nadolol for the treatment of infantile hemangioma. Am J Health Syst Pharm. 2015;72(1):44-6. doi: 10.2146/ajhp140097.

9. Zimmermann AP, Wiegand S, Werner JA, et al. Propranolol therapy for infantile haemangiomas: review of the literature. International Journal of Pediatric Otorhinolaryngology. 2010;74(4):338-42. doi: 10.1016/j.jporl.2010.01.001.

10. Léauté-Labrèze C, Harper JI, Hoeger PH. Infantile haemangioma. Lancet. 2017; 390(10089):85-94. doi: 10.1016/S0140-6736(16)00645-0.

11. Haggstrom AN, Drolet BA, Baselga E, et al. Prospective Study of Infantile Hemangiomas: Clinical Characteristics Predicting Complications and Treatment. Pediatrics. 2006;118,882-887. doi: 10.1542/peds.2006-0413.

12. Léauté-Labrèze C, Prey S, Ezzedine K. Infantile haemangioma: Part II. Risks, complications and treatment. J Eur Acad Dermatol Venereol. 2011;25,12541260. doi: 10.1111/j.1468-3083.2011.04105.x.

13. Novoa M, Baselga E, Beltran S, et al. Interventions for infantile haemangiomas of the skin. Cochrane Database Syst Rev. 2018;4(4):CD006545. doi: 10.1002/14651858.CD006545.pub3.

14. Léauté-Labrèze C, Dumas de la Roque E, Hubiche T, et al. Propranolol for severe hemangiomas of infancy. N Engl J Med. 2008;358(24):2649-51. doi: 10.1056/NEJMc0708819.

15. Taylor RH. Infantile Periocular Haemangioma: Optimising the Therapeutic Response. Paediatr Drugs. 2016;18(3):157-60. doi: 10.1007/s40272-016-01726.

16. Léaute-Labrèze C, Boccara O, Degrugillier-Chopinet C, et al. Safety of Oral Propranolol for the Treatment of Infantile Hemangioma: A Systematic Review. Pediatrics. 2016;138(4):e20160353. doi: 10.1542/peds.2016-0353.

17. Léauté-Labrèze $\mathrm{C}$, Hoeger $\mathrm{P}$, Mazereeuw-Hautier $\mathrm{J}$, et al. A randomized, controlled trial of oral propranolol in infantile hemangioma. $N$ Engl $\mathrm{J}$ Med. 2015;372(8):735-46. doi: 10.1056/NEJMoa1404710.

18. Droitcourt C, Kerbrat S, Rault C, et al. Safety of Oral Propranolol for Infantile Hemangioma. Pediatrics. 2018;141(6):e20173783. doi: 10.1542/peds.20173783.

19. Kunzi-Rapp K. Topical propranolol therapy for infantile hemangiomas. Pediatr Dermatol. 2012;29:154-159. doi: 10.1111/j.1525-1470.2011.01615.x.

20. Püttgen K, Lucky A, Adams D, et al. Topical Timolol Maleate Treatment of Infantile Hemangiomas. Pediatrics. 2016;138(3):e20160355. doi: 10.1542/peds.2016-0355.

21. Goldberg I. Betaxolol. Aust N Z J Ophthalmol. 1989;17(1):9-13. doi: 10.1111/j.1442-9071.1989.tb00483.x.

22. Raphaël MF, de Graaf M, Breugem CC, et al. Atenolol: a promising alternative to propranolol for the treatment of hemangiomas. J Am Acad Dermatol. 2011;65(2):420-421. doi: 10.1016/j.jaad.2010.11.056.

23. Ábarzúa-Araya A, Navarrete-Dechent CP, Heusser F, et al. Atenolol versus propranolol for the treatment of infantile hemangiomas: a randomized controlled study. J Am Acad Dermatol. 2014;70(6):1045-9. doi: 10.1016/j.jaad.2014.01.905.

24. Gumina ME, Yan AC. Atenolol as an alternative to propranolol for the management of sleep disturbances in the treatment of infantile hemangiomas. Pediatr Dermatol. 2019;36(4):556-557. doi: 10.1111/pde.13839.

25. Chantasart D, Hao J, Li SK. Evaluation of skin permeation of $\beta$-blockers for topical drug delivery. Pharm Res. 2013;30(3):866-77. doi: 10.1007/s11095012-0928-9.

26. Zhang Q, Chantasart D, Li SK. Evaluation of $\beta$-blocker gel and effect of dosing volume for topical delivery. J Pharm Sci. 2015;104(5):1721-31. doi: 10.1002/jps.24390.

27. Wassef M, Blei F, Adams D, et al. Vascular Anomalies Classification: Recommendations From the International Society for the Study of Vascular Anomalies. Pediatrics. 2015;136(1):e203-14. doi: 10.1542/peds.2014-3673.

28. Ho NT, Lansang P, Pope E. Topical imiquimod in the treatment of infantile hemangiomas: a retrospective study. J Am Acad Dermatol. 2007;56(1):63-8. doi: 10.1016/j.jaad.2006.06.011.

29. Bauman NM, McCarter RJ, Guzzetta PC, et al. Propranolol vs prednisolone for symptomatic proliferating infantile hemangiomas: a randomized clinical trial. JAMA Otolaryngol Head Neck Surg. 2014;140(4):323-30. doi: 10.1001/jamaoto.2013.6723.

30. Gong H, Xu DP, Li YX, et al. Evaluation of the efficacy and safety of propranolol, timolol maleate, and the combination of the two, in the treatment of superficial infantile haemangiomas. Br J Oral Maxillofac Surg. 2015;53(9):836-40. doi: 10.1016/j.bjoms.2015.09.005.

31. Moyakine AV, Kerstjens JM, Spillekom-van Koulil S, et al. Propranolol treatment of infantile hemangioma (IH) is not associated with developmental risk or growth impairment at age 4 years. J Am Acad Dermatol. 2016;75(1):59-63. doi: 10.1016/j.jaad.2016.02.1218.

32. Langley A, Pope E. Propranolol and Central Nervous System Function: Potential Implications for Paediatric Patients With Infantile Haemangiomas. Br J Dermatol. 2015;172(1):13-23. doi: 10.1111/bjd.13379.

33. Price A, Rai S, Mcleod RWJ, et al. Topical propranolol for infantile haemangiomas: a systematic review. J Eur Acad Dermatol Venereol. 2018;32(12):20832089. doi: $10.1111 /$ jdv.14963.

34. Guo S, Ni N. Topical Treatment for Capillary Hemangioma of the Eyelid Using Beta-Blocker Solution. Arch Ophthalmol. 2010;128(2):255-6. doi: 10.1001/archophthalmol.2009.370. 
35. Hu L, Huang HZ, Li X, et al. Open-label nonrandomized left-right comparison of imiquimod $5 \%$ ointment and timolol maleate $0.5 \%$ eye drops in the treatment of proliferating superficial infantile hemangioma. Dermatology. 2015;230(2):150-5. doi: 10.1159/000369164.

36. Khunger N, Pahwa M. Dramatic response to topical timolol lotion of a large hemifacial infantile haemangioma associated with PHACE syndrome. Br J Dermatol. 2011;164(4):886-8. doi: 10.1111/j.1365-2133.2010.10177.x.

37. McMahon P, Oza V, Frieden IJ. Topical Timolol for Infantile Hemangiomas: Putting a Note of Caution in "Cautiously Optimistic". Pediatr Dermatol. 2012;29(1):127-30. doi: 10.1111/j.1525-1470.2011.01685.x.

38. Moehrle M, Léauté-Labrèze C, Schmidt V, et al. Topical timolol for small hemangiomas of infancy. Pediatr Dermatol. 2013;30(2):245-9. doi: 10.1111/j.1525-1470.2012.01723.x.

39. Pope E, Chakkittakandiyil A. Topical timolol gel for infantile hemangiomas: a pilot study. Arch Dermatol. 2010;146(5):564-5. doi: 10.1001/archdermatol.2010.67.

40. Semkova K, Kazandjieva J. Topical Timolol Maleate for Treatment of Infantile Haemangiomas: Preliminary Results of a Prospective Study. Clin Exp Dermatol. 2013;38(2):143-6. doi: 10.1111/j.1365-2230.2012.04425.x.

41. Chakkittakandiyil A, Phillips R, Frieden IJ, et al. Timolol maleate $0.5 \%$ or $0.1 \%$ gel-forming solution for infantile hemangiomas: a retrospective, multicenter, cohort study. Pediatr Dermatol. 2012;29(1):28-31. doi: 10.1111/j.1525-1470.2011.01664.x.

42. Wu HW, Wang X, Zhang L, et al. Topical Timolol Vs. Oral Propranolol for the Treatment of Superficial Infantile Hemangiomas. Front Oncol. $2018 ; 8: 605$. doi: 10.3389/fonc.2018.00605.

43. Storch $\mathrm{CH}$, Hoeger PH. Propranolol for infantile haemangiomas: insights into the molecular mechanisms of action. Br J Dermatol. 2010;163(2):269-74. doi: 10.1111/j.1365-2133.2010.09848.x.

44. Smith CJF, Friedlander SF, Guma M, et al. Infantile Hemangiomas: An Updated Review on Risk Factors, Pathogenesis, and Treatment. Birth Defects Res. 2017;109(11):809-815. doi: 10.1002/bdr2.1023.

45. Itinteang T, Withers AH, Leadbitter P, et al. Pharmacologic therapies for infantile hemangioma: is there a rational basis? Plast Reconstr Surg. 2011;128(2):499. doi: 10.1097/PRS.0b013e31821b63a0.

\section{Tables}


Table 1

Clincal characteristics of infants

\begin{tabular}{|c|c|c|c|}
\hline Parameters & Classification & $\mathbf{N}$ & $\%$ \\
\hline \multicolumn{4}{|l|}{ Gender } \\
\hline & Female & 52 & 70.27 \\
\hline & Male & 22 & 29.73 \\
\hline \multicolumn{4}{|c|}{$\begin{array}{l}\text { Age at commencement of treatment, months (mean } \pm \\
\text { SD, range) }\end{array}$} \\
\hline & $0-3(1.57 \pm 0.66,0.33-2.90)$ & 33 & 44.59 \\
\hline & $3-6(4.52 \pm 0.88,3.30-5.97)$ & 21 & 28.38 \\
\hline & $6-9(7.50 \pm 0.88,6.06-9.00)$ & 20 & 27.03 \\
\hline \multicolumn{4}{|l|}{ Type } \\
\hline & Plaque & 33 & 44.59 \\
\hline & Nodular & 21 & 28.38 \\
\hline & Dispersive & 20 & 27.03 \\
\hline \multicolumn{4}{|c|}{ Appearance of surface } \\
\hline & Markedly raised & 11 & 14.87 \\
\hline & Raised & 32 & 43.24 \\
\hline & Flat & 31 & 41.89 \\
\hline \multicolumn{4}{|c|}{ Indication for treatment } \\
\hline \multirow[t]{3}{*}{ Risk } & Aesthetic risk & 66 & 89.19 \\
\hline & Functional risk & 8 & 10.81 \\
\hline & Local complication & 0 & 0 \\
\hline \multicolumn{4}{|c|}{ Lesion Location* } \\
\hline & Head and Neck & 27 & 36.49 \\
\hline & Trunk & 22 & 29.73 \\
\hline & Extremities & 25 & 33.78 \\
\hline
\end{tabular}

SD stands for standard deviation.

Classification criteria are in accordance with ISSVA [27].

*Figure 3 describes the precise body parts of infants' IHs and possible high-risks involving them.

Table 2

Clincal response to topical betaxolol hydrochloride relevant to baseline

\begin{tabular}{|c|c|c|c|c|c|c|c|}
\hline & \multirow[t]{2}{*}{ Group } & \multicolumn{4}{|c|}{ Response to treatment } & \multirow{2}{*}{$\begin{array}{l}\text { Effective rate } \\
(\%)\end{array}$} & \multirow[t]{2}{*}{ P-value } \\
\hline & & Excellent & Good & Moderate & Poor & & \\
\hline \multirow[t]{2}{*}{ Gender } & Female & 16 & 30 & 4 & 2 & 88.46 & \multirow[t]{2}{*}{0.402} \\
\hline & Male & 9 & 11 & 2 & 0 & 90.91 & \\
\hline \multirow[t]{3}{*}{ Location of occurrence } & Head and Neck & 8 & 15 & 3 & 1 & 85.19 & \multirow[t]{3}{*}{0.725} \\
\hline & Trunk & 8 & 12 & 2 & 0 & 90.91 & \\
\hline & Extremities & 9 & 14 & 1 & 1 & 92.00 & \\
\hline \multirow{3}{*}{$\begin{array}{l}\text { Age } \\
\text { (months) }\end{array}$} & $0-3$ & 14 & 18 & 1 & 0 & 96.97 & \multirow[t]{3}{*}{$0.002^{*}$} \\
\hline & $3-6$ & 9 & 11 & 1 & 0 & 95.24 & \\
\hline & $6-9$ & 2 & 12 & 4 & 2 & 70.00 & \\
\hline
\end{tabular}

*P $<0.05$ was considered as significant. 
Table 3

VAS results among three age groups after six-month treatment

\begin{tabular}{|c|c|c|c|c|c|c|c|c|c|c|c|c|c|c|}
\hline \multirow{3}{*}{$\begin{array}{l}\text { Age } \\
\text { groups }\end{array}$} & \multicolumn{8}{|l|}{ VAS-C } & \multirow{3}{*}{$\begin{array}{l}\mathrm{P} \text { - } \\
\text { value }\end{array}$} & \multicolumn{5}{|l|}{ VAS-STT } \\
\hline & \multicolumn{2}{|l|}{ Excellent } & \multicolumn{2}{|l|}{ Good } & \multicolumn{2}{|c|}{ Moderate } & \multicolumn{2}{|l|}{ Poor } & & \multicolumn{2}{|l|}{ Excellent } & \multicolumn{2}{|l|}{ Good } & \multirow{2}{*}{$\begin{array}{l}\text { Moderate } \\
\text { Number }\end{array}$} \\
\hline & Number & $\begin{array}{l}\text { Mean } \\
\text { value* }\end{array}$ & Number & $\begin{array}{l}\text { Mean } \\
\text { value }\end{array}$ & Number & $\begin{array}{l}\text { Mean } \\
\text { value }\end{array}$ & Number & $\begin{array}{l}\text { Mean } \\
\text { value }\end{array}$ & & Number & $\begin{array}{l}\text { Mean } \\
\text { value }\end{array}$ & Number & $\begin{array}{l}\text { Mean } \\
\text { value }\end{array}$ & \\
\hline $\begin{array}{l}0-3 \\
\text { months } \\
(n=33)\end{array}$ & 15 & $\begin{array}{l}87.20 \\
\pm 6.20\end{array}$ & 18 & $\begin{array}{l}66.00 \\
\pm 6.36\end{array}$ & 0 & - & 0 & - & $\begin{array}{l}\mathrm{P}= \\
0.001 \text { * }\end{array}$ & 12 & $\begin{array}{l}81.42 \\
\pm 4.65\end{array}$ & 17 & $\begin{array}{l}63.82 \\
\pm 7.23\end{array}$ & 4 \\
\hline $\begin{array}{l}3-6 \\
\text { months } \\
(n=21)\end{array}$ & 12 & $\begin{array}{l}86.83 \\
\pm 7.22\end{array}$ & 8 & $\begin{array}{l}62.75 \\
\pm 6.44\end{array}$ & 1 & 47.00 & 0 & - & & 7 & $\begin{array}{l}81.70 \\
\pm 4.23\end{array}$ & 9 & $\begin{array}{l}60.67 \\
\pm 8.26\end{array}$ & 3 \\
\hline $\begin{array}{l}6-9 \\
\text { months } \\
(n=20)\end{array}$ & 6 & $\begin{array}{l}81.50 \\
\pm 5.25\end{array}$ & 9 & $\begin{array}{l}60.44 \\
\pm 5.46\end{array}$ & 3 & $\begin{array}{l}39.33 \\
\pm 7.36\end{array}$ & 2 & $\begin{array}{l}22.50 \\
\pm 1.50\end{array}$ & & 0 & - & 8 & $\begin{array}{l}63.88 \\
\pm 5.33\end{array}$ & 7 \\
\hline
\end{tabular}

*Mean values were expressed in terms of mean \pm standard deviation.

$* \mathrm{P}<0.05$ was considered as significant.

Table 4

The recordation of blood pressure and heart rate in the topical betaxolol hydrochloride treatment

\begin{tabular}{|c|c|c|c|c|c|c|c|}
\hline \multirow{2}{*}{$\begin{array}{l}\text { Group } \\
\text { Time* }\end{array}$} & \multicolumn{2}{|l|}{$0-3$ months } & \multicolumn{2}{|l|}{ 3-6 months } & \multicolumn{2}{|l|}{ 6-9 months } & \multirow[t]{2}{*}{ P-value } \\
\hline & $\mathrm{BP} *(\mathrm{mmHg})$ & HR (Bpm) & $\mathrm{BP}(\mathrm{mmHg})$ & HR (Bpm) & $\mathrm{BP}(\mathrm{mmHg})$ & HR (Bpm) & \\
\hline Baseline & $\begin{array}{l}73.18 \pm 4.37 \\
35.09 \pm 2.73\end{array}$ & $138.27 \pm 8.32$ & $\begin{array}{l}75.90 \pm 5.22 \\
37.62 \pm 3.26\end{array}$ & $129.05 \pm 8.44$ & $\begin{array}{l}85.05 \pm 4.06 \\
42.75 \pm 3.90\end{array}$ & $115.10 \pm 7.00$ & \\
\hline One month & $\begin{array}{l}74.33 \pm 2.69 \\
36.30 \pm 2.35\end{array}$ & $131.12 \pm 6.46$ & $\begin{array}{l}78.00 \pm 4.48 \\
38.67 \pm 2.17\end{array}$ & $125.10 \pm 5.92$ & $\begin{array}{l}86.25 \pm 4.25 \\
43.80 \pm 3.66\end{array}$ & $110.75 \pm 8.15$ & 0.618 \\
\hline Four months & $\begin{array}{l}79.88 \pm 3.88 \\
39.97 \pm 2.98\end{array}$ & $122.91 \pm 4.25$ & $\begin{array}{l}85.00 \pm 4.68 \\
43.38 \pm 3.15\end{array}$ & $113.52 \pm 7.11$ & $\begin{array}{l}89.50 \pm 3.53 \\
47.10 \pm 3.66\end{array}$ & $102.25 \pm 10.05$ & 0.138 \\
\hline Six months & $\begin{array}{l}85.79 \pm 3.99 \\
42.85 \pm 3.73\end{array}$ & $115.27 \pm 7.74$ & $\begin{array}{l}89.19 \pm 3.00 \\
46.38 \pm 3.15\end{array}$ & $104.62 \pm 6.82$ & $\begin{array}{l}91.95 \pm 3.02 \\
48.10 \pm 3.24\end{array}$ & $95.90 \pm 6.05$ & 0.757 \\
\hline
\end{tabular}

*A total of four times of recordation represented respectively commencement of treatment (baseline); the first follow-up visit (one month later); the second follow-up visit (four month later); the end of treatment (six months). BP, blood pressure, expressed (systolic, diastolic pressure); HR, heart rate; Bpm, beat per minute.

*P $<0.05$ was considered as significant.

Table 5

Pharmacologic properties of betaxolol and timolol

\begin{tabular}{|lll|}
\hline Pharmacologic properties & Betaxolol & Timolol \\
\hline$\beta-1$ adrenergic receptors selectivity & Yes & No \\
\hline Relative $\beta$-blocking potency & 1.0 & $5.0-10.0$ \\
\hline Lipid solubility (Log P) & 2.9 & 1.5 \\
\hline Plasma protein binding potency (\%) & 50 & 10 \\
\hline Intrinsic sympathomimetic activity & No & No \\
\hline
\end{tabular}

*Log P: Octanol water partition (unionized molecules).

\section{Figures}


Infants in the study

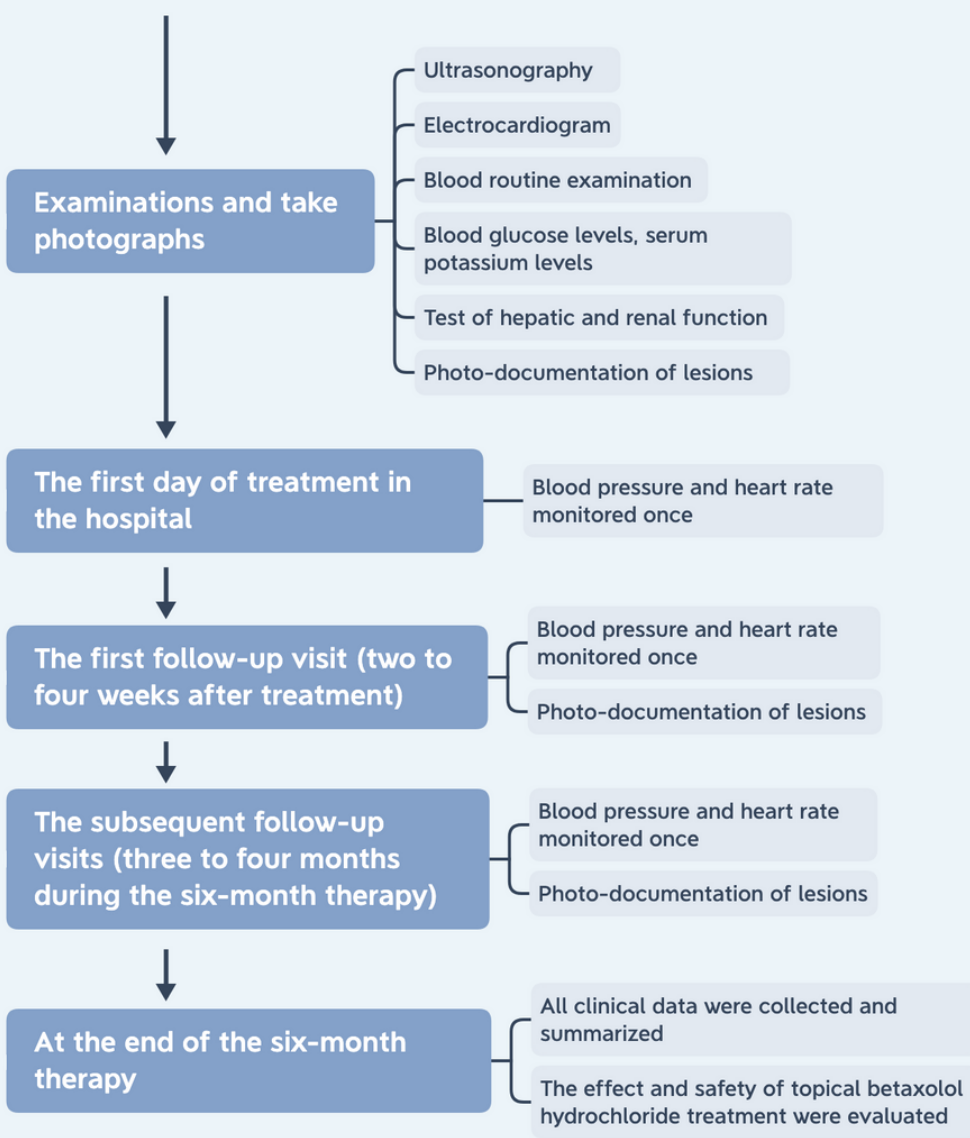

\section{Figure 1}

The chronological flow chart of our study. 
A

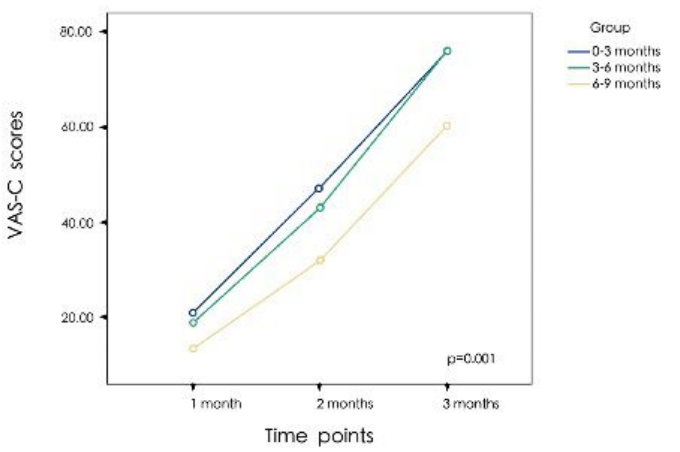

B

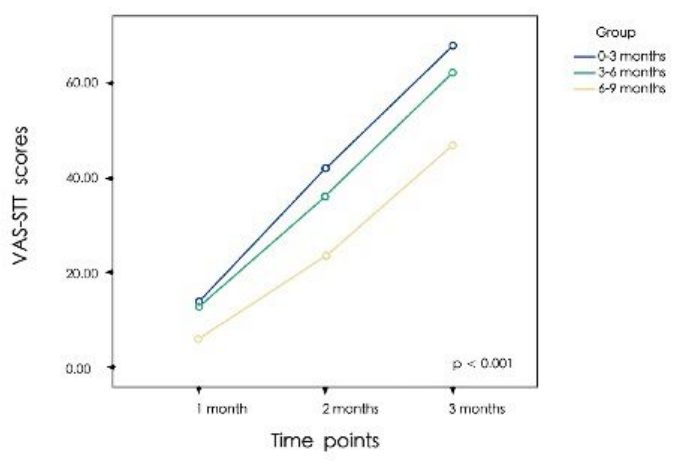

Figure 2

Clinical response to topical betaxolol hydrochloride in superficial IHs over time. (A) is for color (VAS-C score) and (B) is for size, tension and thickness (VASSTT score). 

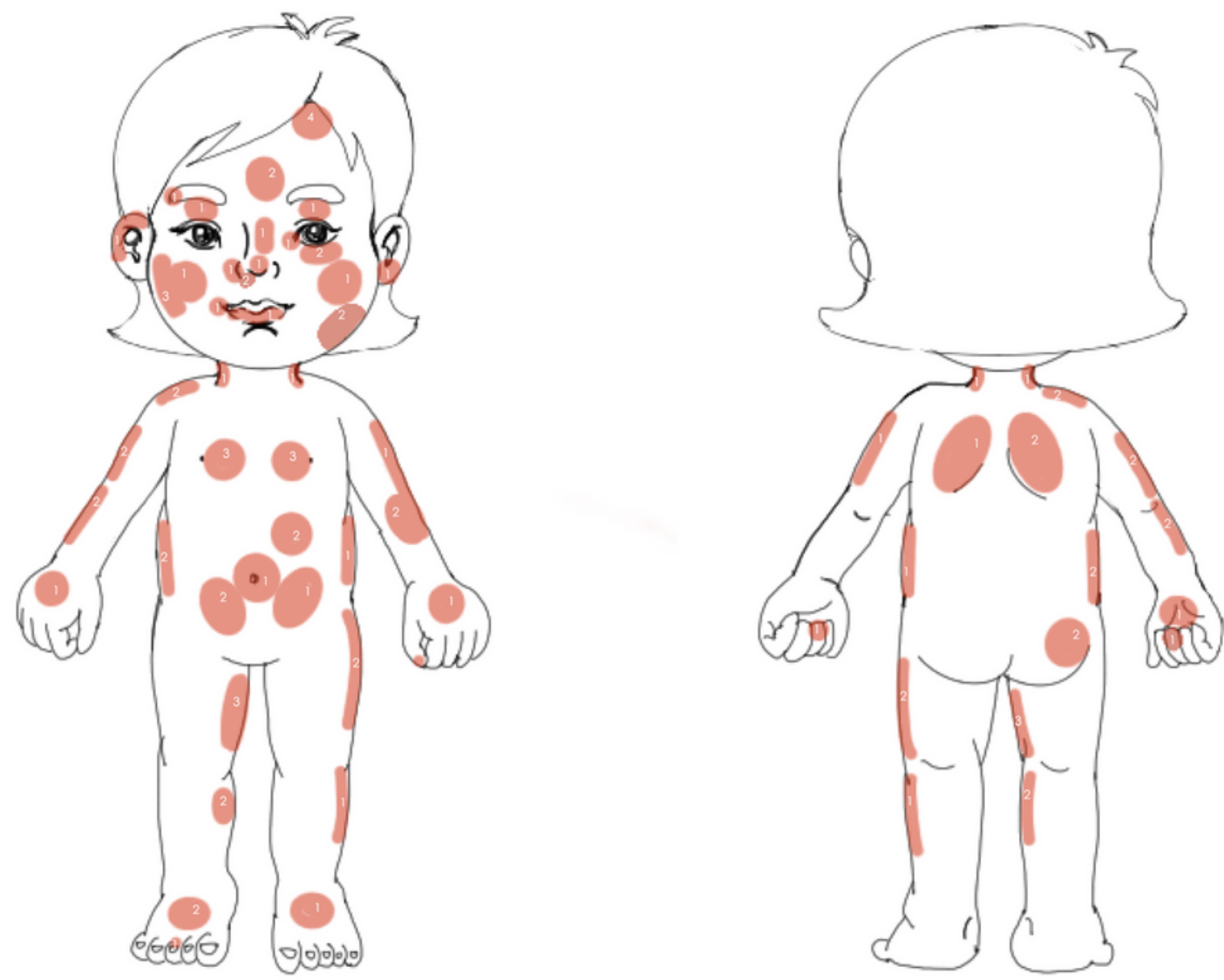

\section{Figure 3}

Description of disease sites of 74 infants and their potential high-risks involved. *The mnemonic PHACE stands for Posterior fossa brain malformations, Hemangioma, Arterial lesions, Cardiac abnormalities, and Eye abnormalities. LUMBAR syndrome* is a disorder defining by the association of skin tag, imperforate anus, lipomyelomeningocele, perineal hemangioma, vesicorenal abnormalities, external genitalia malformations. 


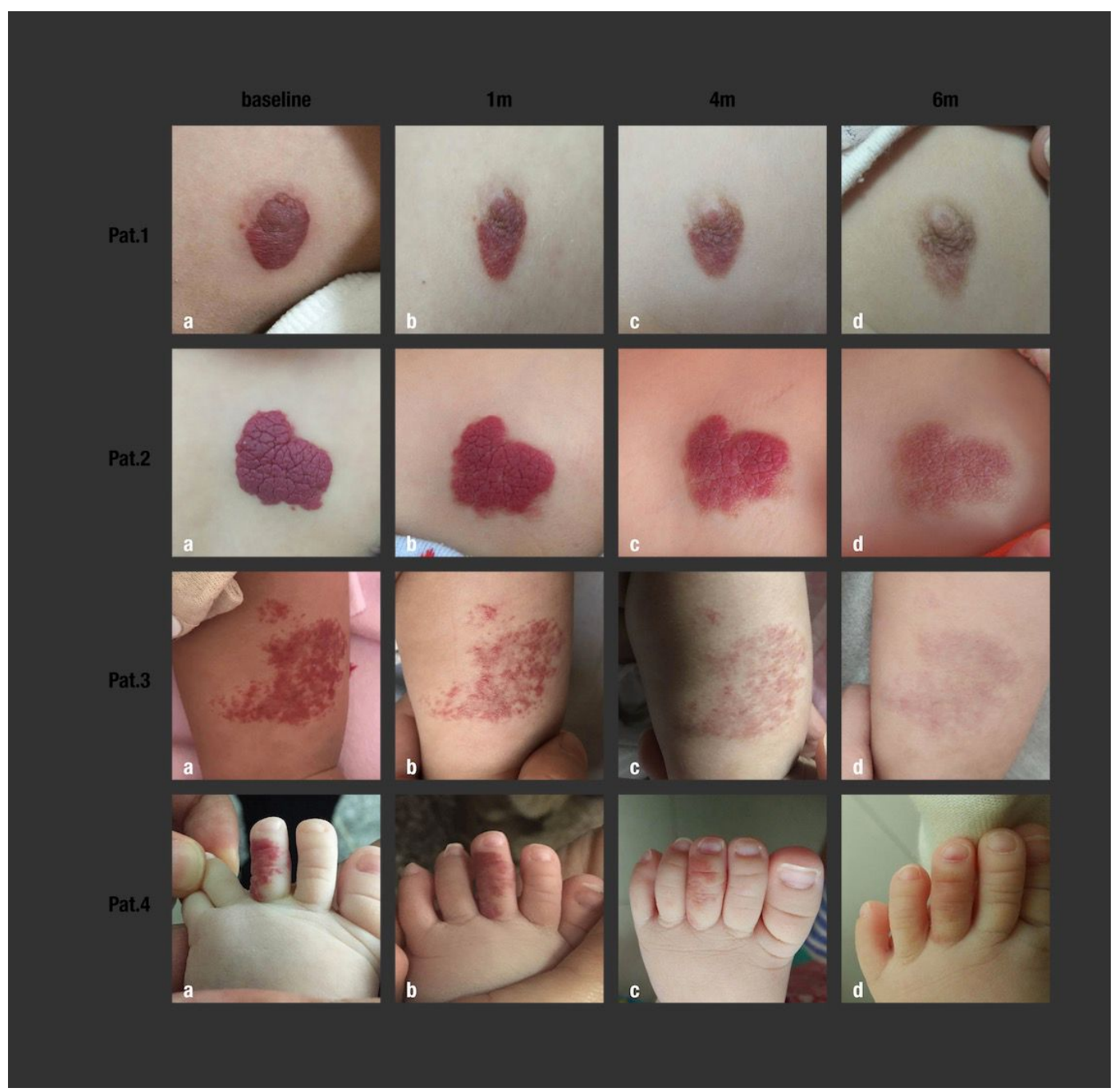

\section{Figure 4}

Photographic data of four independent patients with superficial IHs treated with $0.25 \%$ topical betaxolol hydrochloride. a, b, c, $d$ respectively represents 0 (baseline), 1, 4 and 6 months (end of treatment). Parents or guardians have signed informed consent and agreed with the publication of images.

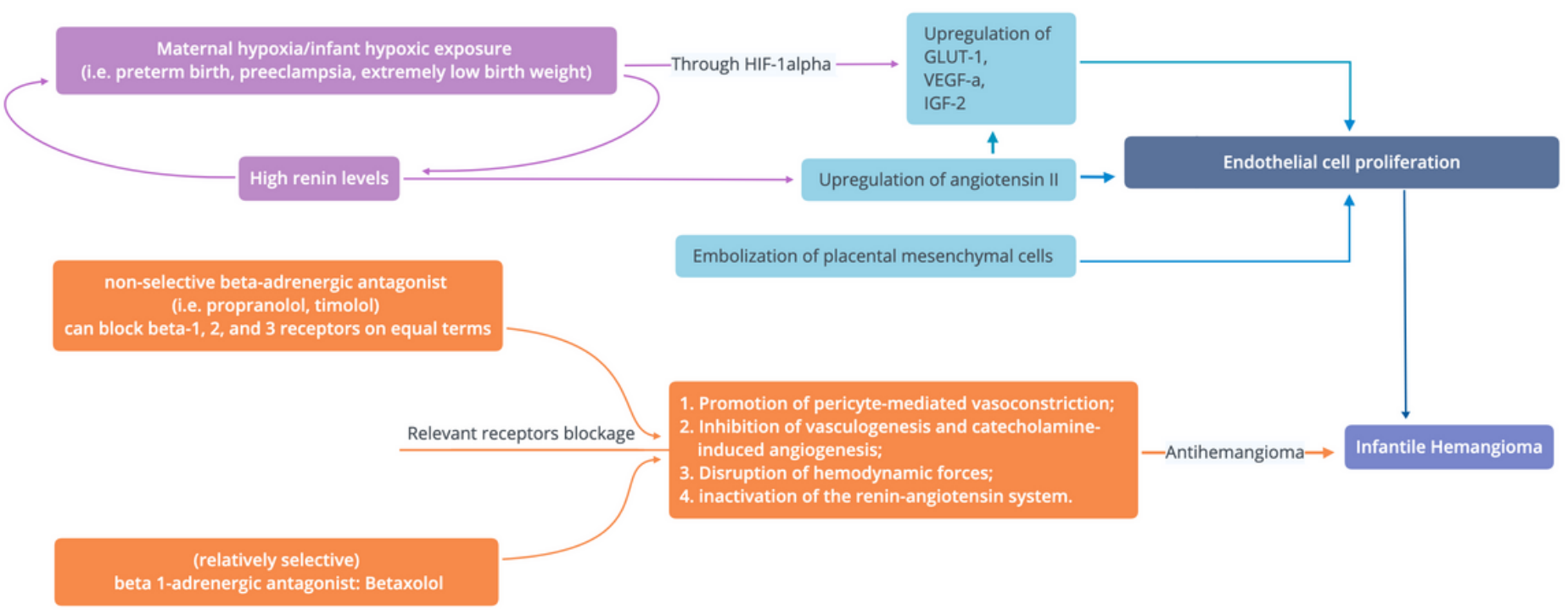

Figure 5 
The interplay among proposed theories of IH pathogenesis. GLUT-1, glucose transporter-1; HIF-1a, hypoxia-inducible factor-1-alpha; IGF-2, insulin-like growth factor 2; VEGF-a, vascular endothelial growth factor a. 